\title{
Dynamic Activities for Managing an IS-Enabled Organizational Change
}

\author{
Taru Salmimaa $\cdot$ Riitta Hekkala $\cdot$ Samuli Pekkola
}

Received: 1 May 2015/Accepted: 2 May 2016/Published online: 21 February 2018

(C) Springer Fachmedien Wiesbaden GmbH, part of Springer Nature 2018

\begin{abstract}
The interpretive grounded theory (GT) study analyses information system (IS) enabled organizational change in two private sector organizations. These two organizations, who are long term partners, were developing a new IS product to divergent markets. The data was gathered through 15 interviews, conducted at the phase of initial rollouts. The findings focus on the results of the theoretical coding phase in which selective codes, referred to as change management activities, are related to each other. As a theoretical contribution, the dynamic structure presents how the change management activities appear differently, depending on a set of choices. Several paradoxical situations stemmed from inconsistencies and/or tensions, because the choices did not support the targeted change management activities. The study thus proposes that there is an increasing demand to analyze the sources of paradoxical situations. Paradoxical situations in these five opposing forces were identified: long term vs. short term, macro vs. micro, past vs. future, centralized vs. distributed, and control vs. trust/self-organization. Some paradoxical situations arose because of the nature of the trust-based IS
\end{abstract}

Accepted after two revisions by Prof. Dr. Bichler.

Electronic supplementary material The online version of this article (https://doi.org/10.1007/s12599-018-0524-6) contains supplementary material, which is available to authorized users.

T. Salmimaa $(\varangle)$ · Prof. S. Pekkola

Tampere University of Technology, 33101 Tampere, Finland

e-mail: taru.salmimaa@gmail.com

Prof. S. Pekkola

e-mail: samuli.pekkola@tut.fi

R. Hekkala

Aalto University School of Business, 00076 Aalto, Finland

e-mail: riitta.hekkala@aalto.fi partnership, while others were socially constructed as a result of unintended consequences of actions in relation to the strategic goals. Managerial efforts are increasingly required for identifying paradoxical situations at an early stage and for considering the right balance for the opposing forces in the dynamic IS change process.

Keywords Actions - Change management activities . Dynamic structure - Grounded theory study · IS change · Paradoxical situations · Opposing forces

\section{Introduction}

This paper presents the results of an interpretative grounded theory (GT) study (Glaser 1992, 1998) in an information system (IS) change process where the participating organizations had conflicting demands for the IS change outcome. The customer and the vendor, the main participant organizations, have collaboratively developed the customer's current IS since the end of the 1990s. The need to renew the ageing IS triggered the change. The customer's long-term business goal was to gain a competitive advantage by supporting the future business model in which a variety of services would be offered along with the product sales. This required different kinds of customizations of the standard platform. The vendor aimed at developing a product that was scalable to a larger customer base. The vendor consequently emphasized the management of customerspecific configurations which can be easily maintained separately from the saleable IS product version. Although the participants had different strategic goals, their trustbased collaboration lasted and evolved over the years.

IS change, also referred to IS-enabled organizational change, has been studied extensively (Heiskanen et al. 
2013; Leavitt 1964; Markus and Robey 1988; Newman and Robey 1992). The research has included, for example, analyzing the relationship between IS and organizational change (e.g., Markus and Robey 1988), analyzing different types of IS change processes in organizations (e.g., Sabherwal and Robey 1995; Van de Ven and Poole 1995), presenting new sense making models (e.g., Lyytinen and Newman 2008), and examining IS change as a continuous process in which the situated actions affect the sociotechnical structures in the IS development (e.g., McLeod and Doolin 2012). Gersick (1991) has highlighted that it is important to understand the changes, no matter what their size, as they can be painful and emotionally difficult, potentially leading to failures (c.f. Allen et al. 2000).

IS change initiatives are often conducted in multi-faceted partner networks where numerous technologies and skillsets are applied for the business benefits (Dittrich 2014; Lyytinen and Newman 2014). The complexity of infrastructures, aligning competing demands, and coping with business and IT units in distributed organizational structures make the IS change an uncertain process (Arvidsson et al. 2014; Guillemette and Paré 2012; Hanseth and Lyytinen 2010; Lyytinen and Newman 2008, 2014). This uncertainty decreases if there are abilities to share knowledge (Carlile 2004), coordinate interrelated tasks across organizational boundaries (Cheng and Fu 2013; Pee et al. 2010), and grow the expertise for business targets (Bassellier and Benbasat 2004). However, the coordination of knowledge sharing with different activities is challenging because the actors contribute at different levels and for different purposes in the organizational context (Lyytinen and Newman 2008). Correspondingly, there are tensions between the actions and the intended IS change goals (Poole and Van de Ven 1989; Smith and Lewis 2011). Hence, to become more responsive, an involvement with coexisting opposing forces is recommended (Lewis et al. 2014).

Our study aims at understanding how to cope with organizational tensions and manage different views during the IS change process. This study was guided by the following research question: what kinds of tensions emerged during an IS change collaboration when trying to manage an IS-enabled organizational change with conflicting strategic goals? We utilize the classic grounded theory (GT) method (Glaser 1992, 1998) with three coding phases (open, selective, and theoretical) (Urquhart and Fernández 2013). The GT coding phases offer a systematic procedure for handling rich data, collected through 15 in-depth interviews (Glaser 1992). From the start of the iterative GT analyzing process, two core categories emerged: (1) 'dynamic activities in the IS change' and (2) 'uncertainty in the IS change'. This paper focuses only on the results of the theoretical coding in the former category.
As a result of theoretical coding, we abstracted five opposing forces: long term vs. short term, macro vs. micro, past vs. future, centralized vs. distributed, and control vs. trust/self-organization. Based on recent literature on paradox (e.g., Smith 2014), these opposing forces can be seen as strategic paradoxes to which strategic responses can be developed. These tensions can thus be regarded as ISchange-specific management aspects that need to be considered, especially in the steering groups and requirements workshops, where critical decisions are made.

We also contribute to existing IS change management literature by constructing a dynamic structure that explains how IS change management activities respond dynamically. Management activities are related to each other through context-specific actions with specific purposes (strategic, managerial, practical), means (artefacts, social arrangements, views), organizational levels (organization, group, individual), and timing (early phase, periodically, throughout the process, etc.). Some inconsistencies and/or tensions emerged when the change management activities were not supported by appropriate actions, and these resulted in paradoxical situations.

The paper is organized as follows. Section 2 presents the relevant literature and concepts. Section 3 describes the research case. Section 4 presents the methodology and explains how the interpretative analysis throughout the GT process has been conducted. Section 5 presents the findings, with descriptions of context-specific actions. The theoretical model of 'dynamic activities for managing an IS change' is also explained here. In Sect. 6, the findings are discussed and integrated with the literature. Key findings and contributions are summarized in Sect. 7, with proposals for future research.

\section{Literature Review}

In this section, the relevant literature is reviewed. Following the grounded theory approach, a 'preliminary literature review' (Urquhart and Fernandez 2006) has not been imposed on the data analysis but has been composed afterwards. There is almost always a need to link emergent concepts or theory with the new literature, and often this involves adding extra literature once concepts from the data are known.

\subsection{Definition of Paradox in the IS Change Context}

When researching paradoxical situations in social realities, for example, in the IS change processes, it is difficult to be unambiguous about the definition of paradox. According to Lewis, paradoxes 'denote contradictory yet interrelated elements - elements seem logical in isolation but absurd 
and irrational when appearing simultaneously' (Lewis 2000 , p. 760). In the social world, however, paradoxes do not consist of exactly contradictory logic (Lewis 2000; Poole and Van de Ven 1989). Additionally, the managerial tendency is often to find solutions to issues instead of accepting the uncertainties that prevail in decision-making when balancing opposing forces (Smith 2014). Hence, paradoxical situations in organizations are often considered as dilemmas in which the advantages and disadvantages can be weighted for a good solution. In the case of a dilemma, each competing alternative has clear advantages and disadvantages (McGrath 1982). In the action research case of Lüscher and Lewis (2008), some managerial situations were considered as solvable dilemmas and were discussed with the managers. However, these situations turned out to be more paradoxical when they were explored in depth.

There is an ontological discussion related to the beliefs of researchers in differentiating paradoxical tensions as being either (1) an inherited feature of a system, or (2) a social construction that emerges in an organizational context when actors are involved in occurrences with their cognition and rhetoric (Smith and Lewis 2011). In an IS change context, when the technologies are embedded in the organizational processes, some material tensions are bounded within the appearances of the practices in an organizational context (Leonardi 2012; Orlikowski 1992, 2007, 2010). This means that some paradoxical situations can be inherited by the use of technologies, especially when the practice with the technologies does not support the work tasks of users. In the social construction view, paradoxical situations mostly emerge in social interactions in which mixed messages or conflicts can come about (Argyris 1988, 1993; Putnam and Poole 1987). As an organizational action can be seen as dualistic in nature, both mindful and mindless behaviors of actors are required for achieving the collective mind in a distributed IS change organization (Carlo et al. 2012). The paradoxical nature of actions is based on the belief that individuals situate tensions in a particular time and space (Poole and Van de Ven 1989), and it provides a reason for considering that there is a strategic response to these paradoxical situations. For example, organizational structures and roles can be arranged in a way such that the tensions can be separated and their differences can be appreciated (Carlo et al. 2012). This acceptance is regarded as a strategic response to the spatial separation (allocating the opposing forces across different organizational units), temporal separation (choosing one pole of tensions at one point in time, and switching later), and synthesis (seeking a view that consolidates the opposing poles) (Poole and Van de Ven 1989).
2.2 Episodic IS Change Process with the Fundamental Choices and Consequences of Actions

In the dynamic business environment in which IS implementing organizations act, there are both external and internal organizational factors that influence the IS change process. Strategic initiation and the wide scope of the IS change typically lead to 'organizational inertia' (Mintzberg and Westley 1992; Stacey 1995), i.e., 'inability for organizations to change as rapidly as the environment' (Pfeffer 1997, p. 163). Organizational inertia forms one of the basic premises for an episodic IS process change (e.g., Lyytinen and Newman 2008) in which both intended and unintended consequences of actions dominate the change process. For example, during the phase when episodic changes occur, an IS change organization is no longer in a condition of equilibrium because of an increasing misalignment between inertial organizational structure and perceived environmental demands (Weick and Quinn 1999). As a result of the misalignment, the IS change process seeks for a replacement, including the configuration of strategic choices, for supporting organizational learning (e.g., Schein 1996). Moreover, many internal factors of an organization explain the episodic nature of the IS change. For example, the outcomes of the IS change can be constrained by the antecedent conditions that are dependent on the nature of the building system, working system, and organizational environment (Lyytinen and Newman 2008). A critical incident causes the phase of 'upheaval' (Gersick 1991; Tushman and Romanelli 1985) when the IS change organization is internally dealing with inconsistencies and instabilities. Both group- and organization-level management actions are needed for equilibrium and stability phases (Gersick 1991; Lyytinen and Newman 2008; Romanelli and Tushman 1994).

In the context of IS change, multi-level models have been developed, such as a punctuated socio-technical IS change model (Lyytinen and Newman 2008, 2014). Depending on a variety of interventions, the outcomes of the events can succeed or fail. For example, in a failed intervention, the misalignments between the fundamental structures are retained. In this situation, the only way to recover from the phase of misalignments is to develop a new deep structure (Gersick 1991; Tushman et al. 1986). The deep structure consists of some fundamental choices of the IS change.

McLeod and Doolin (2012) have studied socio-technical IS development from the perspective of situated actions (e.g., Pettigrew 1990). In practice, the actions conducted in local interaction settings form bases for new socio-technical structures. It has been found that both intended and unintended consequences of actions influence communication and knowledge sharing, negotiation and decision- 
Table 1 The main participating organizations in the IS change

\begin{tabular}{ll}
\hline Customer & $\begin{array}{l}\text { Global service provider in the retail business (over } 1000 \text { employees) who aims to renew the business critical IS covering business } \\
\text { critical functions such as customer service, maintenance, inventory control, resource planning, and finance in } 180 \text { user organizations. } \\
\text { Some customization is needed in all the modules. e.g., a critical business process logic has to take account in all the functions for the } \\
\text { whole IS product design. A significant investor in this IS product development }\end{array}$ \\
Vendor & $\begin{array}{l}\text { National IS provider in enterprise resource planning business for accounting, retail, and chains of shops (over } 80 \text { employees in one } \\
\text { country and further contractors abroad). Module-based IS product development supports an incremental approach in customer } \\
\text { projects. Developing a new IS product on a commercial platform by means of the IS change }\end{array}$
\end{tabular}

making, alignment of divergent goals and expectations of stakeholders, development or sharing of an understanding of the targeted IS, management of conflicting and political aspects, use of technology, and production and exchange of material artefacts (Doolin and McLeod 2012; McLeod and Doolin 2012).

\subsection{Strategic Paradoxes in the IS Change Context}

In the private market, it is believed that organizations need to be able of simultaneously exploring new capabilities for achieving sustainability in the long run and exploiting the current capabilities for maintaining productivity in the short run (March 1991). Thus, simultaneously balancing between exploring and exploiting is an example of a strategic paradox in which appropriate top managers' decisions are necessary especially for resource allocation (i.e., Bower and Gilbert 2005), organization design (i.e., Tushman and Nadler 1992), and product development (i.e., Gatignon et al. 2002) (Smith 2014). In practice, sustainability in the business market is dependent on the abilities of organizations to cope with these two poles.

According to an earlier empirical study (Leonard-Barton 1992), if a product development organization misses an opportunity to be explorative and continuously search for new capabilities, at some point vicious cycles start dominating the new product development. In this vein, Lewis et al. (2002) used the paradoxical lens when studying tensions in new product development. The paradoxical lens provided a conceptual framework for explaining the dynamics and nature of contrasting project management styles. They argued that, in the course of time, project management activities also require updating. With the dynamic arrangement of project roles and responsibilities, sustainability can be achieved in the IS change initiatives with the need for good performance and high-quality results.

Many issues in resource allocation, organization design, and product development create strategic paradoxes which can be managed by focusing on the dynamic decisionmaking structures, instead of being committed only to the decisions made in the early phase (Smith 2014). It has been highlighted that managerial sense making is also needed for working through the paradoxical situations during the change initiatives (Lüscher and Lewis 2008). For example, mid-managers in a change initiative can struggle with their roles as change agents if they are not able to make sense of the real change aims. Hence, providing support for the manager yielded good results in working through the paradoxical situations.

\section{Case Study Description}

This study focuses on an IS change with two private sector organizations (the main actors). Their characteristics are summarized in Table 1. A strategic initiation of IS change was made in order to renew their ageing IS with competitive advantage features (the customer) being developed in collaboration with the customer's long-term IS change partner (the vendor), who was already familiar with the customer's business logic. The vendor had a need to update the technical platform, enabling scalability in order to offer the product to other customers.

During the process (2007-2013), the IS change faced many critical incidents. The most critical one was the fact that the development time while using the new technologies was underestimated. The provision of the value creating features was delayed. The IS change was also put on hold for 1 year because of financial uncertainties. The IS change was re-started in 2010 with the requirements analysis phase, and new actors joined in. At the initial rollout of the first IS version (after Dec 2012), instabilities became dominant. This resulted in doubts concerning the chosen technologies and their opportunities in the long run. When a critical personnel change occurred in the role of IT manager (Jan 2013), prevailing IS change practices had to be reconsidered. Despite some negative feelings among the actors, who saw the negative consequences of incidents, optimism still dominated.

\section{Methodology}

To study the case, 15 interviews (16 interviewees, one session with two interviewees) were conducted by two 
Table 2 Interviewees and their roles in the IS change organization

\begin{tabular}{ll}
\hline Organization & Interviewees (16) and their roles \\
\hline $\begin{array}{l}\text { Customer (11 interview } \\
\text { sessions) }\end{array}$ & Peter, CEO, member of management steering group \\
& John, CTO at the group level, member of management steering group \\
& Jacob, former IT manager, member of management steering group and IS product development steering group (for \\
& a period of half a year), resigned during the initial rollouts \\
& Philip, IT manager, member of management steering group, joined in the initial rollouts \\
& David, head of Business area, participant in requirements workshop \\
& Aiden, head of Functional area, participant in requirements workshop \\
& Matthew, concept owner, participant in requirements workshop \\
& Mary, controller, participant in requirements workshop \\
& Cecilia, user support in IT team \\
& Joseph, technical specialist in IT team \\
& Charlie, head of the user/initial rollout organization, participant in requirements workshop \\
& William, user in the user/initial rollout organization \\
& Christian, CEO, member of management and IS product development steering groups \\
& Daniel, head of Product development, member of IS product development steering group \\
& Sophia, Customer support, member of IS product development steering group \\
& Anthony, senior designer, member of IS product development steering group \\
Vendor (4 interview & \\
sessions) &
\end{tabular}

researchers in spring 2013, 3 years after the IS change was restarted. Each interviewee was asked to describe the IS change process, its progress and challenges from his or her perspective. In other words, they told their own stories that were later analyzed. The interviewees and their roles are described in Table 2.

Orlikowski (1993) argues that the GT methodology is useful for investigating change because of its inductive, contextual, and procedural characteristics. When it is said that GT is inductive, this means that it supports the reasoning process from the ground up, that is, from specific instances in the data to more general conclusions (Urquhart 2012, p. 14). Considering some context-specific nuances (e.g., trust-based relations between key actors) and that our strategic IS change case is a highly complex and dynamic process, we believe it is necessary to develop a new explanatory theory based on the actual experiences of participant actors (Corley 2015; Gregor 2006). In this way, it is possible to immerse in the complex, dynamic, and emergent nature of the research context from the perspective of the actors and to explain how the choices of actors in individual- and group-level actions may conflict with organization-level change aims (Besson and Rowe 2012; Pettigrew 1990; Tsoukas and Chia 2002). Hence, an assumption is that unintended consequences of actions may have dramatic effects on the practical execution of the strategic IS change process.

Glaser (1992) recommends that the researcher takes an open approach in order to ensure that concepts genuinely arise from the data. Glaser $(1992,1998)$ also recommends the collection of rich data, for example in the form of interviews, and the close linking of the data collection with its analysis. We followed the Glaserian GT coding stages: open coding, selective coding, and theoretical coding for the analysis. The first author conducted all these coding phases. Methodological claims and findings were discussed collectively with all authors. In the open coding stage, the interview data was analyzed line by line in Atlas.ti, a software tool for qualitative data analysis. During selective coding and by means of many iterative processes, emergent categories were discovered. As a part of theoretical coding phase, the relationships between selective codes were considered. In this phase, the relations between the selected codes (change management activities) are proposed. The role of theoretical ideas and memos appears important for the theory development as they can explain complex relations (context-specific actions) in the emergent model (Glaser 2005).

\section{Findings}

In this section, we describe the relations between the selective codes (change management activities here) in the core category 'dynamic activities in the IS change' that emerged through the GT analysis. The foundations of the change management activities, consisting of 22 open codes, are presented in the Appendix (available online via http://link.springer.com).

The following sections will present what kinds of strategic actions (e.g., the planning for the IS change vision, the maintenance of long-term IS change aims), 
Fig. 1 The social arrangement (the steering group) in the vendor organization

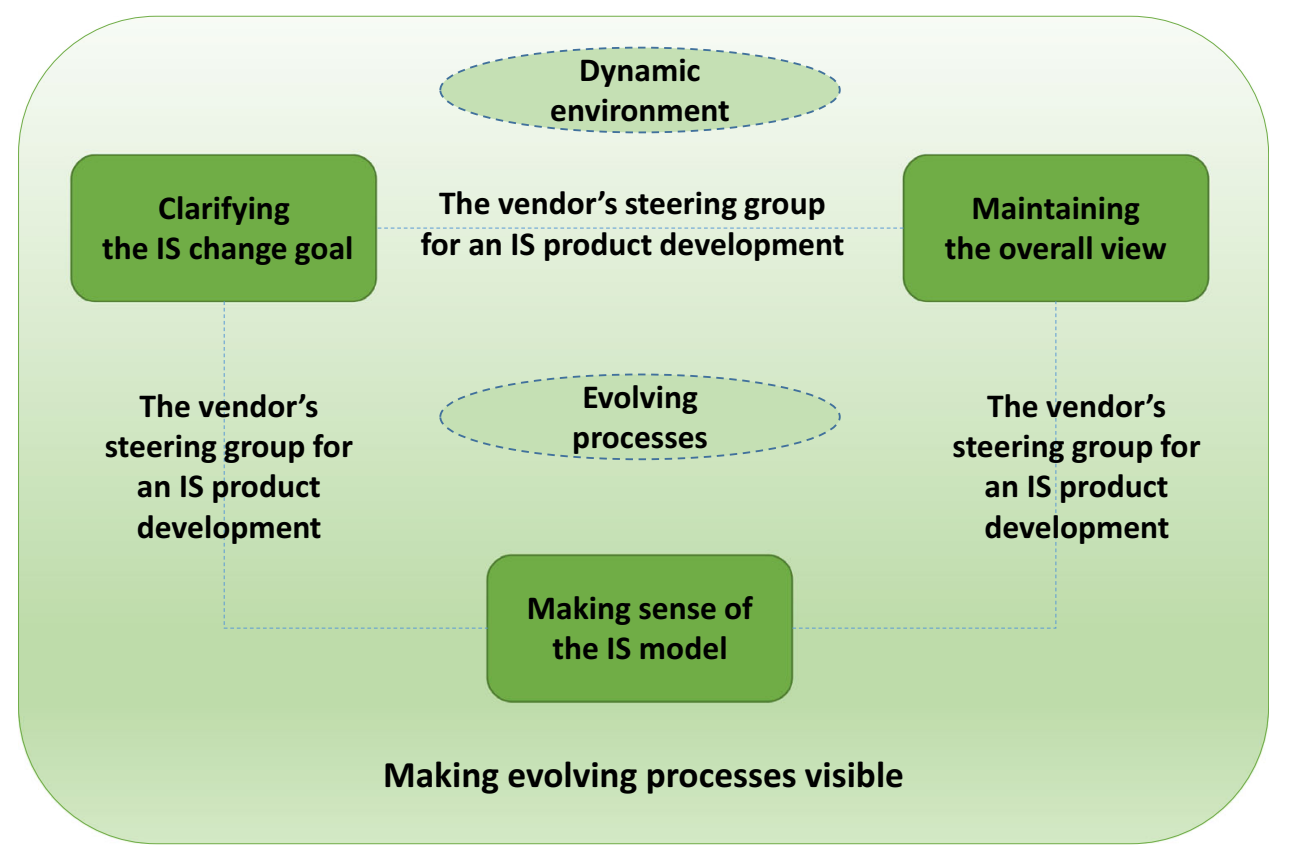

managerial actions (e.g., the control and operationalizing actions toward the IS change, the definition of short-term goals), and practical actions (e.g., the development for the IS product) including different artefacts, social arrangements, and views, occurred at the individual, group or organizational level. As a result of these choices, the context-specific actions may have a variety of outcomes. They influence on the appearance of the change management activities, and explain the dynamic nature of change management structure. In this vein, the change management activities may create different structural forms according to timing, organizational level, purpose, and means of context-specific actions. In the GT process, this is a phase of theoretical coding, in which emergent codes and their relations are abstracted through a reasoning process. This forms a foundation for arriving at new insights and theory development (Glaser 1978, 1992).

\subsection{The Steering Group for a New IS Product Development}

A steering group for the new IS product development was arranged periodically in the vendor office. This action affected the group of actors by involving the CEO and product development team, and the customer representative from the mid-management (Jacob, former IT manager). The purpose of this social arrangement was both managerial and practical. The focus was on making decisions about features and their prioritizing and on resource use and allocation in IS product development. As the new product was expected to provide long-term benefits through IS change, the strategic perspective was emphasized.
When personnel changes occurred during initial rollouts (the customer representative resigned), the strategic view weakened (managerial with the strategic view). The customer representative participated in the steering group only for a short period of time. However, this participation was significant for highlighting the long-term benefits from the customer perspective. '(In the vendor's steering group for a new product development), I was able to emphasize the development orders from the perspective of the customer. I led the opinions when there was a decision point... based on what our expectations are ' (Jacob, former IT manager, customer). Specific mean was the social arrangement (the steering group) where the artefacts and views (e.g., a list of development tasks in a sprint backlog) were applied to share the situational knowledge among the actors. The action aimed to support four different change management activities (see Fig. 1): clarifying the IS change goal (aligning the dissenting views of the customer and the vendor as long as the customer's representative participated in the steering group), maintaining the overall view (making decisions based on the IS change, building on the business fit, managing the customized and standard features, finding the right timing for the change), making sense of the IS model (concretizing the design and getting feedback), and making the evolving processes visible (mapping the road, evolving quality assurance, estimating the time for the machinery tuning).

Figure 1 shows that maintaining the strategic view and alignment of the dissenting IS change goals between the customer and the vendor were significant managerial actions in the steering group. However, after the customer's key midmanager, Jacob (former IT manager, customer), resigned, 
Fig. 2 Sense making with the aid of the 'old' IS logic, although reframing away from the past was also needed

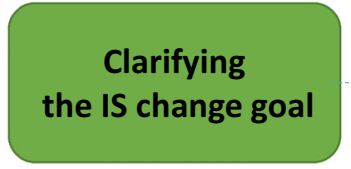

the presence of the customer view weakened. Specifically, the strategic perspective for ensuring that practical actions (decisions about the development orders, and design of the IS model) correspond with the customer's long-term IS change vision was lacking. As the understanding of the outcome of the IS change concretized during the change process, managerial efforts were also needed to make sense of the IS model periodically. Additionally, in the distributed IS change organization, where the business representatives and users were physically dispersed and participated asynchronously, organization-level actions for supporting ad hoc and continuous knowledge sharing among the stakeholders were needed. However, the roadmap and evolving processes (a slow establishment of the testing practices) were visible only to the participants in the internal group-level steering group. This emphasized the presence of the customer's strategic and managerial views from the perspective of the change management.

\subsection{The Design, Sense Making, and Use of the Future IS Logic}

The specifications for the new IS included only a few details how the IS should work in the context. It was assumed (at individual and group levels) that the logic of the new IS should somehow follow the old IS. Thus, the existing logic was not really challenged: 'This (IS change) is partly easy and partly difficult. When the customer has been using the old version, and when the specifications have been fixed, many things have been left unspecified. Of course it has been assumed, by default, that they will be the same as earlier' (Anthony, senior designer, vendor). As a result, a more critical and explorative attitude was needed when evaluating the first roll-out version to determine whether it revealed users' real needs in relation to the new business model. However, only few individuals explored the new IS version or tried to investigate the logic in a comprehensive manner. 'Many users have been scared about failing when using the previous system... For those users, it is very important to show all new opportunities' (Charlie, head of the user organization, customer). More managerial IS change management, such as a facilitation through sense making and reframing, would have been were based on the strategic IS change.

This action attempted to support two different change management activities (see Fig. 2): clarifying the IS needed to ensure that the design and logic of the IS product

\section{Designing and making sense of the future IS logic; Cross-functional workshops}

Making sense of

the IS model change goal (evaluating the real needs of the customer periodically) and Making sense of the IS model (being innovative when designing the IS model, and employing a critical or explorative attitude). However, managerial attempts to steer the users away from the old IS logic toward the future IS logic were only present at the early phase cross-functional requirements workshops. These workshops were not conducted later when the IS change/model became more concrete and the IS production version was already in the piloting stage. Moreover, being diligent with the design artefacts was challenging because of a tight schedule. Individual champion actors (leading designers and the users of the first rollout) tried to makes sense of the IS change, but actions such as using the old system as a reference for practical and short-term purposes often conflicted with long-term objectives.

\subsection{The Management of Expectations and Different Views}

During the IS change process, some mid-managers noted the lack of a roadmap (a shared view) for managing expectations regarding the development phases and progress. '(Strategic and managerial planning) was challenging because the vendor was not able to present a roadmap... (Phasing) was done as hand-to-mouth (for the practical purpose in the IS product development)...' (Jacob, former IT Manager, customer). After the managerial actor, who had strategic understanding and the ability to share knowledge across group boundaries by participating in the most critical decision-making forums, resigned, it became difficult to maintain both macro (strategic) and micro (practical) level views for the decision-making. Many defects were found in the initial rollouts. This and the lack of an appropriately shared view entailed different realities and ignorance of the real state of on-going IS change. This resulted in dissatisfaction among the managers: 'The management steering group (including decision-makers from the customer and vendor, see Table 2) was very close to the global management group (including managers from different IT units responsible for an implementation of IS product in local user organizations across the global [long term] IS change organization)... when information about the IS change (including the progress of development in sub-groups in one country) was not available, dissatisfaction started prevailing among the management in the other countries... They have some 


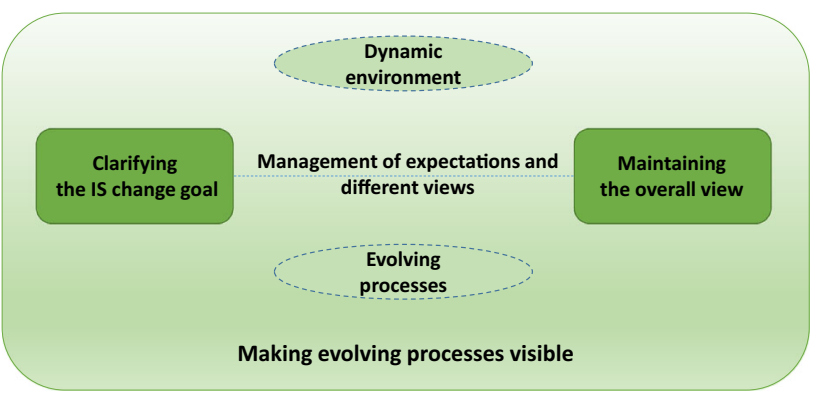

Fig. 3 The need for a shared view (including a roadmap) for managing expectations and different views

specific needs as well...' (Matthew, concept owner, customer).

This action aimed to support three different change management activities (Fig. 3): clarifying the IS change goal (aligning dissenting views [of the purpose of the IS change] as long as the customer's representative participated in the steering group), Maintaining the overall view (making decisions based on the IS change, right timing for the change), and Making the evolving processes visible (mapping the road). As changes took place in the environment regarding social interactions, roles, requirements, and design, it was important to maintain a situational view. The attempt to create a roadmap of information from the macro and micro level views of the change would have required both strategic and managerial efforts to make the roadmap a practical tool for the entire IS change organization.

\subsection{The Evaluation of an IS Product Version}

Evaluating the customer's real needs became easier when the design was concretized and there was a need for regular evaluations: 'I suggested a solution (for the prioritization at the level of organization/group). We should have meetings at short intervals. As our release cycle is two weeks, we have to know what to plan for the next release, and what are the most important points there' (Sophia, Customer support, Vendor). However, these prioritization meetings in the local groups focused on the overwhelming list of defects identified by the users in the piloting phase. Hence, the IS product was too unstable to be evaluated from the IS change perspective.

The instability of the first rollout showed that the testing procedures were evolving too slowly in the vendor's development processes. 'Now we are doing a lot of testing (on behalf of) [the vendor]. We are identifying the defects that they should already have found (in their testing environment)' Peter (CEO, customer). The actions for establishing comprehensive testing procedures did not take

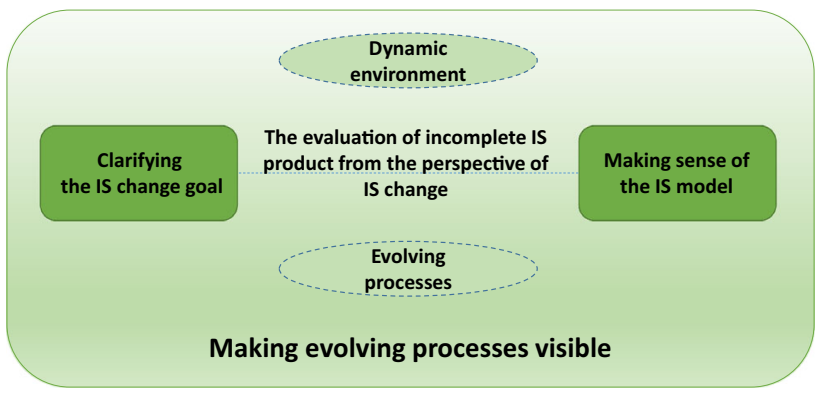

Fig. 4 Recognized periodic evaluation needs were difficult to put into practice with the incomplete IS product

place early enough in the IS change process. Additionally, the first IS version provided hardly any business value for the customer. The actors on the vendor's side focused on the stabilization of the IS version. At the same time, they were aware of a number of customer wishes that had to be implemented in the long run. 'There are still lots of customer wishes about what they want. After the turn of the year, during the piloting, [they express] that they want this and that, but we've gone a bit backwards, and the customer understands it and agrees that we should focus on fixing these' (Sophia, customer support, vendor). Short-term goals contradicted with the long-term IS change goals.

This action aimed to support three change management activities (see Fig. 4): clarifying the IS change goal (evaluating the real needs of the customer periodically), Making sense of the IS model (concretizing the design and getting feedback), and Making the evolving processes visible (evolving quality assurance). There was insufficient managerial support for the group actions (the use of IS version). Strategic IS change should have been evaluated critically with the new IS product version, although it was not completed. The lack of many customized features providing competitive advantage and the slow practical evolution of quality assurance methods created problems.

\subsection{The Issue Management in IS Change and Product Development}

It was challenging to establish a centralized control mechanism for issues because the tool (customer extranet) did not support the practical actions, such as a comprehensive recording and management of identified and preinvestigated problems. In addition, an analysis of their root causes was required for handling the issue efficiently and properly. 'I do not want to sound like a control freak, but I would not allow the users to report defects straight to the customer extranet (provided by the vendor)... I would prefer receiving the issues, first, via email ... I would preinvestigate whether a reported issue was a defect or 
whether it was related to wrong use' (Cecilia, user support in the IT team, customer). Thus, without improvements in the issue management tool and analyzing techniques, it was difficult to empower the user organizations in issue recording.

As more participating user organizations were to join the change process, there was a need for tools and techniques to manage the growing number of issues and changes at the level of organization. '[T]he volume is increasing all the time. So the models of operation that we have had with [the first piloting organization] do not work when we get many offices. For example, I have been exchanging many emails with the end users in [the first piloting organization]. This will not work when there are several offices, and you will drown in the emails. We have to polish our methods along the way. On my part, I have tried to deliver the message that we should get (customer requests, issues) as much as possible through our customer management, so that it is more in control' (Sophia, customer support, vendor).

At the same time, when a lot of issues emerged, concerns about the insufficient requirement specifications were expressed. Some issues were treated as development ideas that have an impact on the design documentation. Many development ideas emerged this way. Yet there was no consistent documentation practice: 'Now we have the practical problem that the ideas are forgotten after the memos are created. Hence, we have a traditional challenge: (how to manage a design process with changes), how to get a centralized tracking of the ideas for advancing with these properly (until the design and work tasks are incorporated into the IS product development)' (Philip, new IT manager, customer). It was not easy to establish a centralized control for emerging requirements and change the design artefacts for the practical actions. For example, the customer's IT team and the vendor's leading designer controlled the preinvestigation of the defects personally. More managerial efforts were necessary for encouraging the actors in the piloting stage and ensuring that the documentation was consistent throughout the process despite poor design practices, quick issue solving, and tight timelines. 'Particularly, I have joined in the middle of the IS change. I have no idea of what had been agreed on earlier in the IS change process. When reviewing the specifications (where something is defined), it is difficult to dig out the information because there is not one document (for example) on how a specific module is supposed (designed) to be used and how the module has been implemented... I've observed that the specifications done with the vendor are insufficient... email conversations (have dominated)... and (the design choices made) have not been officially specified with the descriptions of how and what kind of fields should be used' (Cecilia, user support in the IT team, customer).

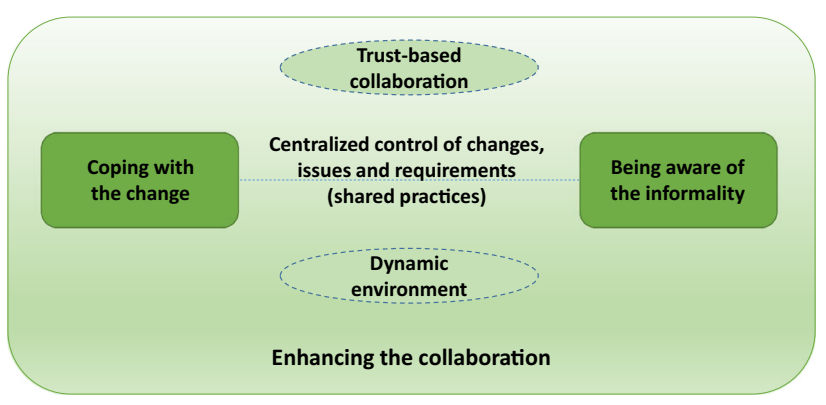

Fig. 5 Centralized control for changes, issues, and requirements during the IS change

This action aimed to support three change management activities (see Fig. 5): coping with the change (encouraging actors in the piloting use), enhancing the collaboration, and being aware of the informality (centralizing the issue management, documenting consistently). However, as long as the managerial efforts were insufficient for establishing a centralized issue reporting tool, it was extremely challenging to control consistent documentation practices (especially for emerging decisions in the design) in a highly dynamic environment, and encourage the actors later in the rollout phase.

\subsection{The Enhancement of Collaboration in the Informal} and Trust-Based IS Change Culture

Throughout the 15-year IS collaboration, the actors used to communicate and coordinate tasks across the organizational boundaries in an informal manner. This was because a limited number of people were able to participate in the IS change process, especially during the maintenance of the previous IS product. 'Jacob had things so well under control because he has such a long history (with the customer) and he was involved with developing the (IS) from the beginning. Now the handling of the whole initiative has been, with [the nickname of IS] and other systems, the big picture has not been under control in the same way even though the IT team is very professional' (Sophia, customer support, Vendor). As a result, a lot of IS change-specific knowledge was only owned by individual actors (like Jacob).

During the IS change process, as the new IS product was developed on the new commercial platform and with the new technologies, some uncertainties emerged and resulted in fit-based concerns related to technologies and how well it was able to support the targeted IS change of the customer. When the new IT manager (Philip) joined (after Jacob's resignation), the informal IS change organization was observed more criticality from the managerial perspective. Although systemizing acts were necessary, e.g. 
for increasing transparency in the release cycles and the development environment and for making realistic decisions about the strategic IS change, the customer wanted to maintain the agility in the managerial and practical actions. 'We do not want to go to some rigid way of developing software based on the literature. Instead, we are looking for agile processes in which it is easy to go back to the (design) decisions made earlier' (Philip, IT manager, customer). More adaptability was needed for development processes in practical actions so that that design was modifiable along the way. At the same time, however, better control was required over the architectural aspects and long-term goal setting for the strategic IS change. For example, the strategic decision-makers in the customer organization also had to be able to (somehow) influence the priorities of the development, although they did not understand the details of the practical actions.

As recognized on the way, formalization was a high priority in the documentation practices because of the distributed IS product development. For example, the distant offshore development had significant responsibilities for some customer-specific functionalities that had to be designed and coordinated in the form of unambiguous design specifications: 'Part of my communication goes to the offshore team where we have developers. I employ them, give them specifications of what to do and make sure that they do what the customer wants... documentation has to be quite specific for them' (Anthony, senior designer, vendor). To share situational knowledge was mostly a responsibility only for few individuals (such as the senior designer and former IT manager) who made informal managerial efforts. The long and trust-based collaboration between the customer and the vendor resulted in asymmetry in knowledge structures. Successful managerial efforts culminated in individual-level actions. 'I communicate with the vendor and with own colleagues in [the country] and [the country] as they are responsible for informing local teams and collecting data accordingly... Of course, I kept [the customer's] managers aware of the status of the (IS change) by participating in the management steering group. Plus, the customer has events where the business management from all the countries meet... Hence, information is shared to this direction too' (Jacob, former IT manager, customer).

This action aimed to support the three different change management activities (see Fig. 6): coping with the change (encouraging actors in the piloting use who faced temporary challenges), being aware of the informality (observing trusted actors and knowledge asymmetries), and enhancing the collaboration (managing the interrelated tasks in the distributed organization, situational knowledge sharing across the boundaries, systemizing the IS change processes without losing the agility). However, during the early phase

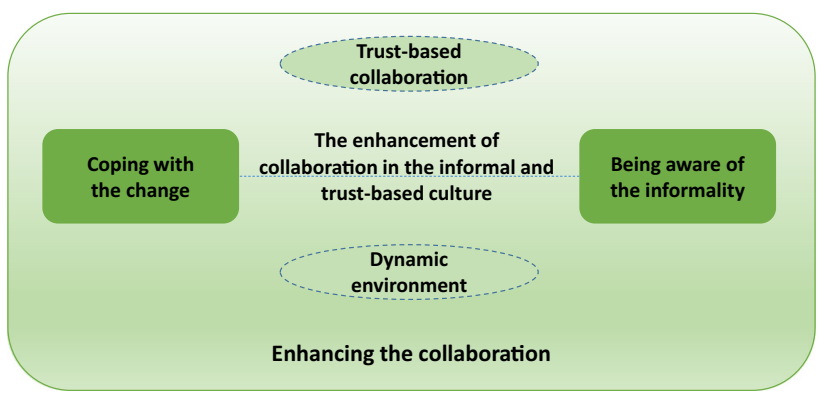

Fig. 6 The enhancement of the collaboration in the informal and trust-based culture

of the IS change process, when the informality supported the collaboration (despite the asymmetry), possible risks with the current ways of managing the IS change were not taken seriously. Knowledge gaps were observed much later in the IS change process, when fundamental changes occurred in the managerial actions. In practice, after Jacob (former IT manager) left, there were not abilities to understand and control the IS product development from the perspective of the customer's IS change vision. Situational knowledge sharing was lost when Jacob (a key boundary spanner) left. As a result, the new IT manager wished to have more formal and transparent processes to ensure that the strategic aims could also be accounted for in the IS product development, and the operationalization acts (managerial efforts) took time. The new actors had to gain the trusts of the other actors first and understand the prevailing organization culture that was difficult to change.

\subsection{The Management Steering Group for the Strategic IS Change}

A management steering group was arranged periodically for making decisions about the long-term strategic planning and scheduling within the IS change. The participant actors were mostly the top managers and key decision-makers in the IS change (such as CEOs of both customer and vendor, CTO, and the IT manager, who was the main person responsible for the managerial actions for the IS change). In practice, the former IT manager (Jacob) acted as a proxy person in the management steering group. By being involved in both micro- and macro-level actions, he was able to integrate knowledge from the different sub-processes (such as the decisions in the steering group for the IS product development) to inform top managers about the practical progress of the IS change. Jacob (former IT manager) also communicated actively with the customer's CEO: 'Jacob got in touch with me every week or even on a daily basis to tell me about different kinds of things... I can say that I was aware of the problems or challenges emerging (during the IS change)... I also knew where they were going' (Peter, CEO, Customer). 
This action aimed to support all the emerging change management activities in the structure (see Fig. 7) as the decisions made in the management steering group defined the constraints of the IS change process: the overall schedule, budget, and resources. In addition, the long-term goals of the IS change were discussed and evaluated against the real situation. The top managers, as a part of awarding systems at the corporate level, had to ensure that the targeted business benefits were possible. Hence, the IS change management structure, in which the activities are supported with the context-specific actions, can be seen as a view of the management steering group if it consists of the information about the real actions and the outcomes of those actions in the IS change organization.

When conceptualizing the relationships, specific actions (which means artefacts, social arrangements, and views at the level of individual and group) make it is easy to highlight a number of choices (practical actions) which easily become separated from the strategic IS change goals. These are summarized in the emergent model (Fig. 7) as a result of the theoretical coding phase.

In many actions, the managerial efforts were not sufficient to consider all the relevant aspects from the perspective of the strategic IS change. For example, many design choices were not evaluated sufficiently from the perspectives of business and targeted IS change because of the tight schedule that demands quick issue solving and light design. In the distributed IS change organization, where the participants come from different organizations or organizational units, it easily happens that the practical actions in self-organized distributed teams are less controlled because of the cultural and geographical distances between them. When informality is supported, local practices start prevailing, which challenge better managerial control for strategic IS change. Although the trust-based culture evolved during years of collaboration (between the customer and the vendor), informality was enhanced in the knowledge sharing and coordination. It was easy to ignore the managerial control aims from the perspective of strategic view just for short-term goals, such as a stable IS version.

Finding the right set of appropriate strategic, managerial, and practical actions is essential for successful IS change. The rationalization of the choices can be challenging when constraints occur, such as a limited number of participating actors, an ambiguous schedule of IS change, and the new technologies have been applied to the IS product development. Hence, finding the right set of means (artefacts, social arrangements, and views), organizational levels (organization, group, individual), purposes (strategic, managerial, practical), and timing for the specific actions can also be restricted.

\section{Discussion}

In this section, our findings are discussed with regard to the related literature, and some practical and theoretical implications are considered. Seven change management activities (selected codes) that emerged in GT analysis were related to each other and formed the core category of 'dynamic activities in the IS change'. The theoretical coding phase, where the relations were rationalized, produced the theoretical model (Fig. 7). In summary, Fig. 7 illustrates in how far the appearance of the IS change management structure depends on the purposes (strategic, managerial, practical), the means (artefacts, social arrangements, views), the organizational levels (organization, group, individual), and timing (e.g., early phase, periodically, at the initial rollout) of context-specific actions. These are the choices the actors made during the IS change process.

Next, we summarize the findings and explain how the purposes, means, organizational levels, and timings of actions influence the appearance of the IS change management. In order to make sense of these paradoxical situations at a higher level of abstraction, we categorized them under the following opposing forces (as presented in Table 3).

- Long term vs. short term: how the steering groups (management and IS product development) are able to plan for a short-term IS product version and a long-term IS change simultaneously;

- Macro level vs. micro level: how the decision-makers are able to integrate both macro- and micro-level views throughout the IS change;

- Past vs. future: how the participants in the requirements workshops use their experiences with the existing IS product and tend to lean on the 'past' IS logic what is not necessary right for the future business model;

- Centralized vs. distributed: how the IS product development is able to improve the practices for centralized prioritization and issue management as well as for a distributed problem solving and development of tasks; and

- Control vs. trust/self-organization: how the management is able to select the appropriate means to control the IS product development from the perspective of the IS change such that the emergent requirements, learning, and self-organized efforts are not restricted during design and development.

In the trust-based IS partnership between the customer and the vendor that evolved during 15 years of collaboration, the individuals and groups had more decision-making power for their own actions due to self-organization. In this kind of setting, it was tempting to continuously create new 


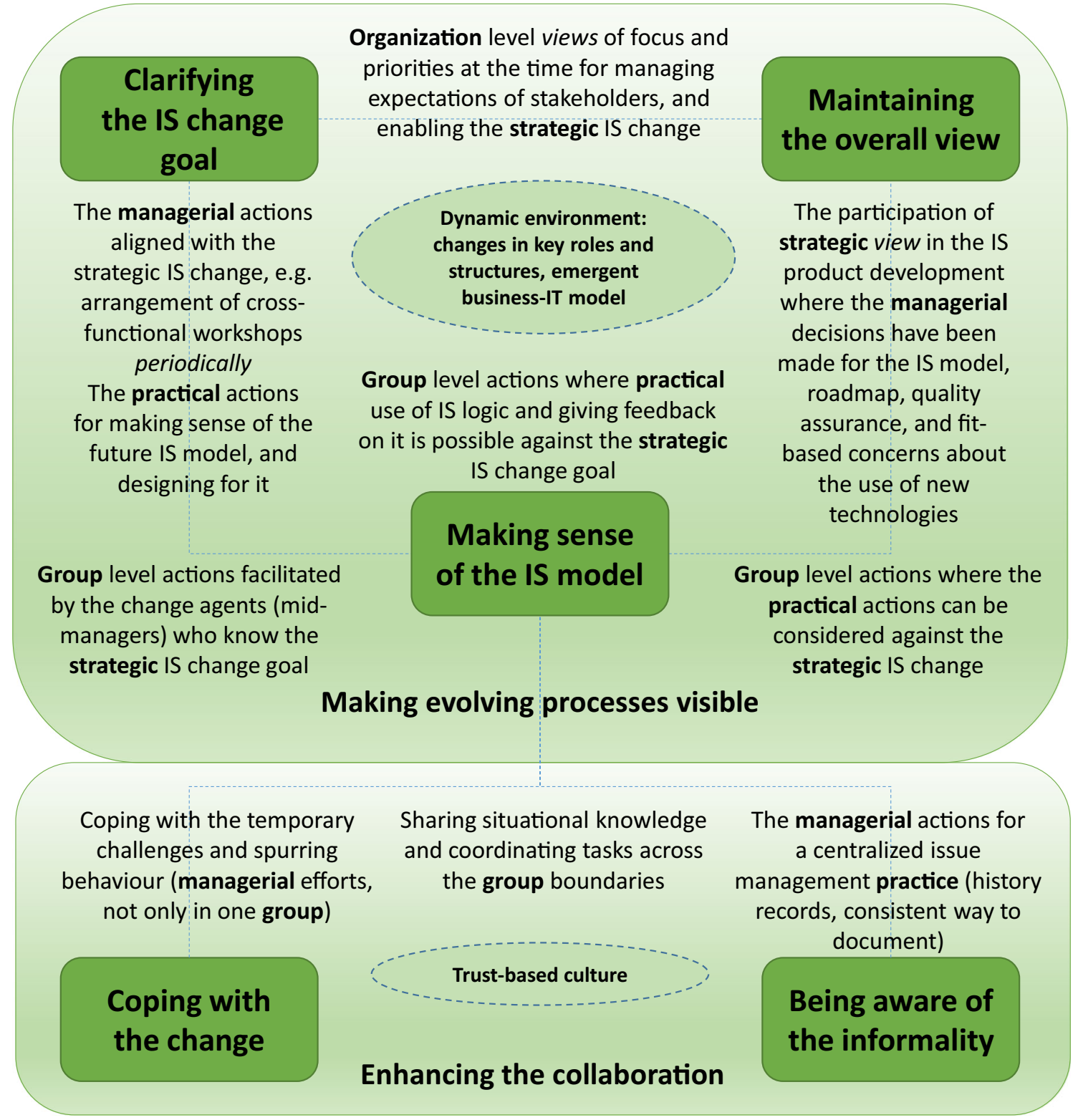

Fig. 7 The management steering group in which all the seven change management activities should be related through the appropriate actions for making decisions about the strategic IS change in the long run

interactions for practical purposes without thinking of the strategic purpose of the IS change, and maintain productivity only for short-term goals. Hence, different kinds of local practices, including ways to learn and conduct design practices, were enhanced even by the IS change organization's own institutional rules (e.g., Seo and Creed 2002). In the course of time, it was difficult to control the actions in the self-organized groups, although the outcome of the actions was not acceptable (such as an unstable IS version). This was concretized after the critical changes in the managerial roles and actions. For example, the resignation of a mid-manager, who was a boundary spanner (Fisk et al. 2010; Levina and Vaast 2005) across the group boundaries, made the alignment of macro (strategic IS change) and micro (IS product development) level views challenging. At the same time, negative emotions were experienced among the actors, as the incomplete IS product in the piloting stage did not support an evaluation of the IS product and its real constraints. At the phase of initial rollouts, when a number of defects was identified in the IS product, more control over the IS product development (group actions) was requested by the customer's management.

Informal community-based modes of control such as clan control (i.e., shared values, beliefs, and philosophies within a group of individuals) may enhance collaboration and support paths towards the targeted IS change goal 
Table 3 Summary of context-specific actions and the paradoxical situations at the higher level of abstraction in relation to purpose, organizational level, and timing of the IS change

\begin{tabular}{lll}
\hline Actions & Purposes/level & Paradoxical situations \\
\hline 5.1 The steering group for a new IS & Managerial, & Short term thinking and goal setting when making
\end{tabular}

5.1 The steering group for a new IS Managerial, product development practical/group

5.2 The design, sense making, and use of the future IS logic

5.3 The management of expectations, and the different views for the IS change

5.4 The evaluation of an IS product from the perspective of IS change

5.5 The issue management in the IS change and product development

5.6 The enhancement of the collaboration in the informal and trust-based IS change culture

5.7 The management steering group for making decisions about the long term goals and schedule
Managerial, practical/group, individual

Strategic, managerial, practical/ organizational, group, individual

Strategic, managerial, practical/group, individual

Managerial, practical/ organizational, individual

Strategic, managerial, practical/ organizational, group, individual

Strategic, managerial/ organizational, group
Short term thinking and goal setting when making
decisions about the development tasks, resources, and machinery tuning phases for the upcoming releases of the IS product version

Long term thinking (strategic) and facilitation (managerial) were limited from the perspective of customer's business

"Old" (Past) IS logic dominated the analysis and design during the requirements workshops because of limited managerial (group level) facilitation and technical competence to make sense of the future IS model

Insufficient artefacts to make sense of the future business logic with the new technologies applied to the development. Old system was a reference

When balancing between the macro (the strategic IS change) and micro (the development of the IS product) level views, it was managed successfully with the aid of individual level boundary spanning until the initial rollouts

No road map (a shared view at the macro level) for the IS change process at the organization level

The tight schedule and the overwhelming list of defects/issues identified in the first IS version led to short term goal setting in the IS product development. Long term strategic business benefits were difficult to evaluate with the incomplete IS product version in the initial rollouts

The customer extranet (a centralized tool) did not support a comprehensive recording of issue descriptions and knowledge sharing in the distributed IS product development. A lack of managerial effort was needed for improving the tools that would support the right balance between centralization (tracking, prioritization) and distribution (pre-investigation of issues)

Adding control over the vendor's IS product development was challenging in the trust-based IS change culture and partnership, especially because of the key actor changed. Yet the new IT manager (Philip) with the strategic purpose to systemize the IS change process had not as much managerial power and knowledge and self-organized practices were dominant

Long term planning required a realistic view of the IS change progress at the macro level. Situational knowledge was shared with the aid of one boundary spanner (Jacob) who was able to inform the management steering group about the micro level actions and short term decisions in the IS product development as long as he was a part of the IS change
Timing

Periodically (customer's representative participated for a short period of time)

Early phase (the aid of champion acting)

Periodically (less formal clarifications periodically)

Early phase (the aid of boundary spanning and champion acting)

At the phase of initial rollouts

At the phase of initial rollouts

At early phase, after the first initial rollout (when actor changes occurred)

Periodically (a realistic view of the overall IS change only at the early phase) 
tight in our case, an increasing number of defects was not acceptable. Hence, in order to manage the IS change toward the strategic IS change vision, the right managerial and practical actions were needed for balancing between the trust-based informal (clan, self-control) and formal (behavior, outcome) modes of control. As observed in our case, paradoxical situations emerged as there were many choices in actions which were contradictory to the targeted structure. In this way, the antecedent conditions, or historical reasons for the trust relations between the customer and the vendor, turned out to be critical for the IS change process (Lyytinen and Newman 2008).

As to the strategic aims in our case, uncertainties about the possibilities with new technologies limited the decision-making at the early phase. For example, in the requirements workshops, a group of actors from different knowledge areas aimed to design the future IS model and business benefits in the long term. However, the right kind of supportive artefacts and/or sufficient managerial efforts toward these aims were not available. The actors mostly referred to the IS logic learnt in the existing (past) IS product. As Lüscher and Lewis (2008) argue, there is a need for change agents in organizational change initiatives. However, as change agents are often limited by their role of mid-managers (a stable organizational role), they may struggle with shifting organizational expectations during the change process (Huy 2002; Lüscher and Lewis 2008). For example, in our case, Jacob (former IT manager, Customer) was committed to the change agent role by arranging the cross-functional requirements workshops and advancing the requirements specifications for the future IS model. As the technical knowledge was limited to the perspective of the customer's business models in the phase of the requirements workshops, however, mismatches started emerging at the phase of initial rollouts. Accepting possible constraints was difficult among all the key players in the initiative. Any radical change in the process (e.g., technical platform change) would have slowed down the development of the IS product's customized features ahead of the competitors.

Instead of aiming at finding solutions to the paradoxical situations that emerge in organizations, paradox researchers (Lewis 2000; Lüscher and Lewis 2008; Poole and Van de Ven 1989; Smith and Lewis 2011; Smith 2014) have recommended the use of strategic responses when coping with these opposing forces. For example, with aid of acceptance (i.e., keeping tensions separate and appreciating their differences) and resolution (i.e., spatial or temporal separation, or synthetization) (Poole and Van de Ven 1989), paradoxical situations can be worked through in a constructive way among the decision-makers during an IS change. Hence, as in our case, the decision-makers should have put more effort on the identification of paradoxical situations and opposing forces so that the right strategic responses could be considered and put into the practice. For example, knowledge integration capability (e.g., Mitchell 2006) of the self-organized groups was recognized as a critical feature for the organization-level decision-making.

As the IS change management structure has a highly dynamic nature, the IS change management activities within the structure are balanced only for a short period in the equilibrium phase (Gersick 1991). Hence, re-alignments of actions with organization-level goals is periodically necessary. Awareness of organizational tensions, which can also be obstructed by socio-cognitive aspects of actors (excessive trust, informal mode of controls, clans) (Besson and Rowe 2012), is one of the managerial efforts required for finding the right balance during the dynamic IS change.

\section{Conclusion}

In this paper, we have presented the results of the theoretical coding using classic GT analysis based on data collection from 15 in-depth interviews. Our research aim was to study an IS change process and find an answer to the research question: what kinds of tensions emerges in an IS change collaboration when trying to manage an IS-enabled organizational change with conflicting strategic goals? In our case, the long-term strategic aim of the IS change initiative was to develop the business benefits for both main participant organizations - the customer and the vendor. More responsive change management activities were required for balancing between the differentiation (customer) and standardization (vendor) goals within the new IS product development. In addition, continuous interaction and negotiation between the key actors were necessary for clarifying the IS change goal throughout the IS change process.

By means of the open and selective coding phases, we have identified seven selective codes, including the distribution of 22 open codes (Supplementary Appendix). During the theoretical coding phase, the selective codes, referred to as change management activities, were related to each other through the context-specific actions and constituted the dynamic structure of the IS change management (see Fig. 7). As a theoretical contribution, the findings show that change management activities have different appearances in a structure because the actions consist of the different choices made by the participant actors in the IS change. In practice, depending on the specific purposes (strategic, managerial, practical), on the specific means (artefacts, social arrangements, views), on the specific organizational levels (organization, group, individual), and on the timing (e.g., early phase, 
periodically, continuously) applied to the actions, the IS change management has different appearances. In the context of dynamic activities, a dynamic structure constitutes one of the main concerns for managing an IS-enabled organizational change. The context-specific actions, identified as the roots of paradoxical situations (see Table 3 ) in the theoretical coding phase (Sect. 5), were integrated into the existing literature with the five opposing forces (Sect. 6): long term vs. short term, macro vs. micro, past vs. future, centralized vs. distributed, and control vs. trust/selforganization. Based on this, the managerial implications were drawn.

In our case, in which a trust-based partnership was established between the customer and the vendor, it seemed to be difficult to achieve organizational transparency without the active involvement of the individual-level champion. For example, the resignation of the boundary spanner (Levina and Vaast 2005) and change agent (Lüscher and Lewis 2008) triggered vicious cycles (Akkermans and van Helden 2002; Forrester 1995; Luna-Reyes et al. 2005). The critical knowledge (a real status of new IS products) was culminated only at individual and group level, but did not reach the organization level without the boundary spanning. Specifically, when aiming to balance between the macro- and micro-level views (and also shortterm and long-term goals simultaneously) for making decisions based on the overall view, participation in different decision-making forums was necessary. Moreover, the distributed organization was affected by the resource allocation in which the limited number of business representatives were able to participate in the IS change after the early phase requirements workshops. Most IS product development activities were conducted by the customer's IT team and the vendor's experts. The distributed IS change organization was one of the sources of many paradoxical situations because there were no centralized practices established to share knowledge efficiently across the group and organizational boundaries, and the different views of stakeholders were not evaluated enough for the evolving IS product. At the phase of initial rollouts, the instability of the first version of the IS product was realized, which is why there was a desire to increase control over the development practices. For example, the tools and techniques applied to quality assurance required reconsideration. However, increasing the formal mode of controls in the trust-based culture with informal practices took time.

In our case, in an optimal situation the management steering group should have succeeded in taking a stable view of the IS change management structure periodically, and in this way should have geared the IS change activities towards the strategic IS change vision. However, as also shown in earlier studies (Lyytinen and Newman 2008, 2014; McLeod and Doolin 2012), there are always some unintended consequences of actions within the sociotechnical IS change process. In this vein, the dynamic structure of IS change management with seven change management activities itself became a paradoxical view to the actors who participated in the IS change management. As researched recently in the context of strategic management, the decision-makers should be able to engage with the opposing forces in the organizational context if aiming to cope with strategic paradoxes such as the alignment of divergent stakeholders' goals and the ability to explore new technologies and simultaneously develop features within the tight schedule (Smith 2014).

In future research, it would be interesting to analyze the meanings of the context-specific actions based on the theory of situated actions (Pettigrew 1990) in the different contexts. In addition, the roots of paradoxical situations (inherited vs. socially constructed) should be studied in depth to see how these change over time. For example, they could be specified in the timeline of an IS project. An analysis of how the history, culture and organizational inertia aspects of an IS project effect on practices could also be conducted. In addition, the dynamic behavior of the IS change management structure could be further explored. For example, proposals on how to engage with opposing forces for strategic responses in IS change/product/project management could be examined for further developing the theoretical model.

\section{References}

Akkermans H, van Helden K (2002) Vicious and virtuous cycles in ERP implementation: a case study of interrelations between critical success factors. Eur J Inf Syst 11(1):35-46

Allen DK, Colligan D, Finnie A, Kern T (2000) Trust, power and interorganizational information systems: the case of the electronic trading community TransLease. Inf Syst J 10(1):21-40

Argyris C (1988) Crafting a theory of practice: the case of organizational paradoxes. In: Quinn RE, Cameron RS (eds) Paradox and transformation: toward a theory of change in organization and management. Ballinger, Cambridge, pp 255-278

Argyris C (1993) Knowledge for action: a guide to overcoming barriers to organizational change. ERIC Number: ED357268. ISBN-1-55542-519-4, p 309

Arrow KJ (1985) Informational structure of the firm. Am Econ Rev 75(2):303-307

Arvidsson V, Holmström J, Lyytinen K (2014) Information systems use as strategy practice: a multi-dimensional view of strategic information system implementation and use. J Strateg Inf Syst 23(1):45-61

Bassellier G, Benbasat I (2004) Business competence of information technology professionals: conceptual development and influence on IT-business partnerships. MIS Q 28(4):673-694

Besson P, Rowe F (2012) Strategizing information systems-enabled organizational transformation: a transdisciplinary review and new directions. J Strateg Inf Syst 21(2):103-124 
Bower JL, Gilbert CG (eds) (2005) From resource allocation to strategy. Oxford University Press, Oxford

Carlile PR (2004) Transferring, translating, and transforming: an integrative framework for managing knowledge across boundaries. Organ Sci 15(5):555-568

Carlo JL, Lyytinen K, Boland RJ Jr (2012) Dialectics of collective minding: contradictory appropriations of information technology in a high-risk project. MIS Q 36(4):1081-1108

Cheng J, Fu Y (2013) Inter-organizational relationships and knowledge sharing through the relationship and institutional orientations in supply chains. Int J Inf Manag 33(3):473-484

Chua CEH, Lim W, Soh C, Sia SK (2012) Enacting clan control in complex IT projects: a social capital perspective. MIS Q 36(2):577-600

Corley KG (2015) A commentary on "What grounded theory is..." engaging a phenomenon from the perspective of those living it. Organ Res Methods 18(4):600-605

Dittrich Y (2014) Software engineering beyond the project-sustaining software ecosystems. Inf Softw Technol 56(11):1436-1456

Doolin B, McLeod L (2012) Sociomateriality and boundary objects in information systems development. Eur J Inf Syst 21(5):570-586

Eisenhardt KM (1985) Control: organizational and economic approaches. Manag Sci 31(2):134-149

Fisk A, Berente N, Lyytinen K (2010) Boundary spanning competencies and information system development project success. In: Proceedings of the 31 st international conference on information systems, St. Louis, pp 1-14

Forrester JW (1995) The beginning of system dynamics. McKinsey Q $4: 17$

Gatignon H, Tushman ML, Smith W, Anderson P (2002) A structural approach to assessing innovation: construct development of innovation locus, type, and characteristics. Manag Sci 48(9):1103-1122

Gersick CJ (1991) Revolutionary change theories: a multilevel exploration of the punctuated equilibrium paradigm. Acad Manag Rev 16(1):10-36

Glaser BG (1978) Theoretical Sensitivity: Advances in the Methodology of Grounded Theory. The Sociology Press, California

Glaser BG (1992) Basics of grounded theory analysis. Sociology Press, Mill Valley, California

Glaser BG (1998) Doing grounded theory: issues and discussions. Sociology Press, California

Glaser BG (2005) The grounded theory perspective III: Theoretical coding. Sociology Press, California

Gregor S (2006) The nature of theory in information systems. MIS Q 30(3):611-642

Guillemette MG, Paré G (2012) Toward a new theory of the contribution of the IT function in organizations. MIS Q 36(2):529-551

Hanseth O, Lyytinen K (2010) Design theory for dynamic complexity in information infrastructures: the case of building internet. J Inf Technol 25(1):1-19

Heiskanen A, Hekkala R, Newman M, Eklin M (2013) The sociotechnical change and PSIC models as lenses to view three consecutive public sector is projects. In: Proceedings of European conference on information systems. http://aisel.aisnet.org/ ecis2013_cr/35/. Accessed 26 Jan 2018

Huy QN (2002) Emotional balancing of organizational continuity and radical change: the contribution of middle managers. Adm Sci Q 47(1):31-69

Kirsch LS (1997) Portfolios of control modes and IS project management. Inf Syst Res 8(3):215-239

Kirsch LJ, Sambamurthy V, Ko D, Purvis RL (2002) Controlling information systems development projects: the view from the client. Manag Sci 48(4):484-498
Leavitt HJ (1964) Applied organization change in industry: structural, technical and human approaches. In: Cooper WW, Leavitt HJ, Shelly MW (eds) New perspectives in organization research. Wiley, New York

Leonard-Barton D (1992) Core capabilities and core rigidities: a paradox in managing new product development. Strateg Manag J 13(S1):111-125

Leonardi PM (2012) Materiality, sociomateriality, and socio-technical systems: what do these terms mean? How are they related? Do we need them? In: Leonardi PM, Nardi BA, Kallinikos J (eds) Materiality and organizing: social interaction in a technological world. Oxford University Press, Oxford, pp 25-48

Levina N, Vaast E (2005) The emergence of boundary spanning competence in practice: implications for implementation and use of information systems. MIS Q 29(2):335-363

Lewis MW (2000) Exploring paradox: toward a more comprehensive guide. Acad Manag Rev 25(4):760-776

Lewis MW, Welsh MA, Dehler GE, Green SG (2002) Product development tensions: exploring contrasting styles of project management. Acad Manag J 45(3):546-564

Lewis MW, Andriopoulos C, Smith WK (2014) Paradoxical leadership to enable strategic agility. Calif Manag Rev 56(3):58-77

Luna-Reyes LF, Zhang J, Gil-García JR, Cresswell AM (2005) Information systems development as emergent socio-technical change: a practice approach. Eur J Inf Syst 14(1):93-105

Lüscher LS, Lewis MW (2008) Organizational change and managerial sense making: working through paradox. Acad Manag $\mathrm{J}$ 51(2):221-240

Lyytinen K, Newman M (2008) Explaining information systems change: a punctuated socio-technical change model. Eur J Inf Syst 17(6):589-613

Lyytinen K, Newman M (2014) A tale of two coalitions-marginalising the users while successfully implementing an enterprise resource planning system. Inf Syst J 25(2):71-101

March JG (1991) Exploration and exploitation in organizational learning. Organ Sci 2(1):71-87

Markus L, Robey D (1988) Information technology and organizational change: causal structure in theory and research. Manag Sci 34(5):583-598

McGrath JE (ed) (1982) Dilemmatics: the study of research choices and dilemmas. Judgment Calls in Research. Sage Publications Beverly Hills, CA, pp 69-80

McLeod L, Doolin B (2012) Information systems development as situated socio-technical change: a process approach. Eur J Inf Syst 21(2):176-191

Mintzberg H, Westley F (1992) Cycles of organizational change. Strateg Manag J 13(S2):39-59

Mitchell VL (2006) Knowledge integration and information technology project performance. MIS Q 30(4):919-939

Newman M, Robey D (1992) A social process model of user-analyst relationships. MIS Q 18:249-266

Orlikowski WJ (1992) The duality of technology: rethinking the concept of technology in organizations. Organ Sci 3(3):398-427

Orlikowski WJ (1993) CASE tools as organizational change: investigating incremental and radical changes in systems development. MIS Q 17(3):309-340

Orlikowski WJ (2007) Sociomaterial practices: exploring technology at work. Organ Stud 28(9):1435-1448

Orlikowski WJ (2010) The sociomateriality of organizational life: considering technology in management research. Camb J Econ 34(1):125-141

Ouchi WG (1979) A conceptual framework for the design of organizational control mechanisms. Manag Sci 25(9):833-848

Pee LG, Kankanhalli A, Kim H (2010) Knowledge sharing in information systems development: a social interdependence perspective. J AIS 11(10):550-575 
Pettigrew AM (1990) Longitudinal field research on change: theory and practice. Organ Sci 1(3):267-292

Pfeffer J (1997) New directions for organization theory: problems and prospects. Oxford University Press, New York

Poole MS, Van de Ven AH (1989) Using paradox to build management and organization theories. Acad Manag Rev 14(4):562-578

Putnam LL, Poole MS (1987) Conflict and negotiation. In: Jablin FM, Putnam LL, Roberts KH, Porter LW (eds) Handbook of organizational communication. Sage, Newbury Park

Romanelli E, Tushman ML (1994) Organizational transformation as punctuated equilibrium: an empirical test. Acad Manag J 37(5):1141-1166

Sabherwal R, Robey D (1995) Reconciling variance and process strategies for studying information system development. Inf Syst Res 6(4):303-327

Schein EH (1996) Kurt Lewin's change theory in the field and in the classroom: notes toward a model of managed learning. Syst Practice 9(1):27-47

Seo M, Creed WD (2002) Institutional contradictions, praxis, and institutional change: a dialectical perspective. Acad Manag Rev 27(2):222-247

Smith WK (2014) Dynamic decision making: a model of senior leaders managing strategic paradoxes. Acad Manag J 57(6):1592-1623

Smith WK, Lewis MW (2011) Toward a theory of paradox: a dynamic equilibrium model of organizing. Acad Manag Rev 36(2):381-403
Stacey RD (1995) The science of complexity: an alternative perspective for strategic change processes. Strateg Manag J 16(6):477-495

Tsoukas H, Chia R (2002) On organizational becoming: rethinking organizational change. Organ Sci 13(5):567-582

Tushman M, Nadler D (1992) Designing organizations that have good fit: a framework for understanding new architectures. In: Gerstein M, Nadler D, Shaw R (eds) Organization architecture. Jossey-Bass, San Francisco, pp 39-56

Tushman M, Romanelli E (1985) Organizational evolution: interactions between external and emergent processes and strategic choice. Res Organ Behav 8:171-222

Tushman ML, Newman WH, Romanelli E (1986) Convergence and upheaval: managing the unsteady pace of organizational evolution. Calif Manag Rev 29(1):29-44

Urquhart C (2012) Grounded Theory for qualitative research: a practical guide. SAGE Publications

Urquhart C, Fernandez WD (2006) Grounded theory method: the researcher as blank slate and other Myths. In: The International Conference on Information Systems, 2006 Milwaukee, WI, USA

Urquhart C, Fernández W (2013) Using grounded theory method in information systems: the researcher as blank slate and other myths. J Inf Technol 28(3):224-236

Van de Ven AH, Poole MS (1995) Explaining development and change in organizations. Acad Manag Rev 20(3):510-540

Weick KE, Quinn RE (1999) Organizational change and development. Ann Rev Psychol 50(1):361-386 